\title{
The Ability of Environmental Context to Facilitate Psychomotor Sensitization to Amphetamine Can Be Dissociated from Its Effect on Acute Drug Responsiveness and on Conditioned Responding
}

Hans S. Crombag, Ph.D. ${ }^{1}$, Aldo Badiani, M.D. ${ }^{2}$, Jacqueline Chan, B.S., James Dell'Orco, B.S., Sean P. Dineen, B.S., and Terry E. Robinson, Ph.D.

Doses of amphetamine or cocaine that fail to induce psychomotor sensitization when given to a rat in its home cage can produce robust sensitization if given immediately following placement into a relatively novel, distinct environment. A drug-associated context can serve as a conditioned stimulus, and therefore may promote robust sensitization by facilitating associative learning processes. We examined this hypothesis by habituating rats to the test environment for 1 or 6-8 hr prior to each drug injection, which degrades the ability of environmental context to serve as an effective conditioned stimulus. When $0.5 \mathrm{mg} / \mathrm{kg}$ of amphetamine was administered intravenously immediately after placement into a distinct environment there was a large acute psychomotor response (rotational behavior) on the first test day, and robust sensitization developed with repeated daily injections. When the same treatment was administered in the home cage, there was a small acute response and no sensitization developed. The enhanced acute response seen in the distinct environment was significantly attenuated by $1 \mathrm{hr}$ of habituation to the test environment, and completely abolished by 6-8 hr of habituation. Also, as little as $1 \mathrm{hr}$ of habituation completely prevented the development of a conditioned rotational response. In contrast, neither 1 nor 6-8 hr of habituation had any effect on the ability of amphetamine to induce robust behavioral sensitization. It is concluded that the ability of a distinct environment to facilitate sensitization to amphetamine can be dissociated from its effect on acute drug responsiveness and from the ability of drug-associated environmental stimuli to elicit a conditioned response. Possible mechanisms by which a distinct environment facilitates sensitization are discussed.

[Neuropsychopharmacology 24:680-690, 2001] (C) 2001 American College of Neuropsychopharmacology. Published by Elsevier Science Inc.
From the Department of Psychology (Biopsychology Program), The University of Michigan, Ann Arbor, MI.

Address correspondence to: Dr. Terry E. Robinson, University of Michigan, Department of Psychology, East Hall, 525 East University, Ann Arbor, MI 48109-1109. Tel.: (734) 763-4361; Fax: (734) 7637480; E-mail: ter@umich.edu

Received July 11, 2000; revised November 15, 2000; accepted November 15, 2000.

${ }^{1}$ Present address: Behavioral Neuroscience Branch, National Institute of Drug Abuse, Baltimore, MD.
KEY WORDS: Psychostimulant drugs; Behavioral sensitization; Rotational behavior; Habituation; Novelty; Context; Learning; Conditioning; 6-Hydroxydopamine; Stress; Rat

Behavioral sensitization, an increase in drug effect produced by repeated intermittent treatments, has received

${ }^{2}$ Present address: Department of Human Physiology and Pharmacology, University of Rome "La Sapienza", Rome, Italy. 
increasing attention because the neural changes underlying sensitization to drugs of abuse may contribute to addiction (Lett 1989; Piazza et al. 1989; Robinson and Berridge 1993). In studying the conditions that facilitate or retard sensitization we have found that the context in which drugs are administered has a large effect on their ability to induce psychomotor sensitization (Badiani et al. 1995a, 1995b; Robinson et al. 1998, for review). For example, doses of amphetamine, cocaine, or morphine that fail to induce psychomotor sensitization when given in the home cage, induce robust sensitization when given in a distinct and relatively novel environment (Badiani et al. 2000b; Browman et al. 1998a, 1998b; Crombag et al. 1996).

The mechanisms responsible for the facilitation of sensitization by a distinct environment are not known, but it is tempting to relate them to associative learning processes (Badiani et al. 1995a, 1995b). Indeed, it has been suggested that sensitization may be the result of a progressive increase in the ability of treatment-related stimuli to elicit a conditioned response (CR), which adds to the unconditioned drug response (UR) (Hinson and Poulos 1981; Pert et al. 1990; Tilson and Rech 1973). If this hypothesis is correct, manipulations that degrade the ability of contextual stimuli to acquire conditioned stimulus (CS) properties should attenuate the facilitation of sensitization that occurs when drugs are administered in a distinct environment. Increasing the interval between presentation of the would-be CS and the unconditioned stimulus (US) is known to impair conditioning (Kimble 1947; Pickens and Crowder 1967). Therefore, in the present experiment we studied the effect of increasing the CS-US interval on the development of sensitization produced by amphetamine, by habituating rats to the test environment prior to drug administration. The psychomotor stimulant effects of repeated intravenous (i.v.) injections of amphetamine were assessed by quantifying rotational behavior in rats with a unilateral 6-OHDA lesion. Injections were given (1) in the absence of any environmental stimuli predictive of drug administration (HOME groups); (2) immediately after rats were placed into a distinct environment (NOVEL groups); or (3) in a distinct environment, but after either 1 or 6-8 hr of habituation to that environment ( $1 \mathrm{hr}$ and 6-8 hr HABITUATION groups). Intravenous injections of amphetamine were given using remote-controlled syringe pumps. Thus, amphetamine was administered in the absence of the aversive stimuli associated with other routes of experimental drug administration (e.g., appearance of an experimenter, handling, needle jab).

\section{MATERIALS AND METHODS}

\section{Subjects and Behavioral Measure}

Male Sprague-Dawley rats (Harlan Sprague Dawley, Indianapolis, IN), weighing 200-225 g on arrival were individually housed in steel-wire hanging cages in a climate-controlled animal colony, which was maintained on a 14:10 hr light:dark cycle (lights on at 08:00). Food and water were available ad libitum. Rats were acclimatized to the animal colony for at least 7 days prior to surgery. All training and testing took place during the light phase of the light/dark cycle. Experiments were carried out in accordance with the "Guide for the Care and Use of Laboratory Animals" as adopted by the National Institutes of Health.

The psychomotor stimulant effects of amphetamine were quantified by measuring amphetamine-induced rotational behavior in rats with a unilateral 6-hydroxydopamine (6-OHDA) lesion of the nigrostriatal dopamine pathway. As previously discussed (Badiani et al. 1995a; Crombag et al. 1999), the quantification of rotational behavior in rats with a unilateral lesion provides a number of methodological advantages over more traditionally used measures of psychomotor activation, such as locomotor crossover activity and/or stereotyped behavior in neurologically intact rats. For example, in rats with a unilateral lesion a progressive increase in drug effect is characterized by a linear increase in rotational behavior over a wide range of doses of amphetamine (Crombag et al. 1999). In contrast, amphetamine produces a linear increase in locomotor crossover activity only over a small range of doses (Crombag et al. 1999). Furthermore, rotational behavior is particularly advantageous in studies investigating the effects of environment on psychomotor stimulant sensitization, because the unconditioned rotational response produced by exposure to a novel test environment is negligible, whereas the locomotor crossover response can be substantial (Badiani et al. 1995a).

\section{Surgical Procedures}

This experiment was conducted using three independent squads of animals (with groups balanced across squads), and there were small differences in surgical procedures between squads. As described below, in two squads the 6-OHDA lesion was made via a chronically implanted guide cannula and the catheter was fixed to the skull, and in one squad the lesion was made at the time of surgery and the catheter attached to a backport. All other procedures were identical across squads. Detailed methods are given only for those that received a chronic guide cannula.

Rats were pretreated with atropine and then anesthetized with sodium pentobarbital supplemented with methoxyflurane when necessary. Using standard stereotaxic procedures a 21-gauge stainless steel guide cannula was positioned over the medial forebrain bundle (3.0 $\mathrm{mm}$ posterior to bregma, $1.8 \mathrm{~mm}$ lateral to bregma, and $1.0 \mathrm{~mm}$ ventral to the skull surface), counter-balancing left and right hemispheres. A 15-gauge length of 
stainless steel tubing and a length of polyethylene tubing, both bent at a $90^{\circ}$ angle, were positioned on the skull surface. These served later as the support for a tether and as a guide for the intravenous catheter, respectively. The entire assembly was affixed to the skull surface using 4 jeweler screws and dental cement. The guide cannula was capped with a stainless steel stylet. After at least 3 days of recovery rats received a unilateral 6-OHDA lesion of the nigrostriatal dopamine pathway by lowering a 29 gauge infusion cannula through the guide cannula ( $8.3 \mathrm{~mm}$ ventral to the skull surface) and infusing $8 \mu \mathrm{g}$ of $6-\mathrm{OHDA}$ over $8 \mathrm{~min}$. To protect noradrenergic terminals rats were pretreated with desipramine 20 to $30 \mathrm{~min}$ prior to lesioning (Breese and Traylor 1971). The infusion cannula was left in place an additional $2 \mathrm{~min}$ to reduce diffusion of the 6-OHDA up the cannula tract. Rats were returned to the animal colony following the lesion. Some animals received the lesion at the time of the surgery (see below).

Ten days after the lesion rats were screened for the development of dopamine receptor supersensitivity by administering $0.05 \mathrm{mg} / \mathrm{kg}$ apomorphine subcutaneously, and measuring contraversive rotational behavior. This dose of apomorphine produces vigorous circling behavior only when over $90 \%$ of the dopaminergic terminals in the striatum have been depleted unilaterally (Hefti et al. 1980; Marshall and Ungerstedt 1977). Rats that 10 min after treatment made fewer than 5 full rotations / $\mathrm{min}$ were re-lesioned and re-screened using identical procedures. Rats that did not pass either screening test were excluded from the study.

Finally, intravenous catheters were implanted using procedures described previously (Crombag et al. 1996; Weeks 1972). Briefly, catheters were constructed from silastic tubing $(0.30 \mathrm{~mm} \mathrm{ID}, 0.64 \mathrm{~mm}$ OD) and two sizes of polyethylene tubing $(0.38 \mathrm{~mm}$ ID, $1.09 \mathrm{~mm}$ OD and $0.28 \mathrm{~mm}$ ID, $0.61 \mathrm{~mm}$ OD) as described by Weeks (1972). Rats were anaesthetized with a combination of ethyl ether (to induce anesthesia) and methoxyflurane (to maintain anesthesia) and the silicone end of the catheter was inserted into the right external jugular vein. The polyethylene end of the catheter exited dorsally through the nape of the neck or between the shoulders, and one of two methods was used to fix the external end of the catheter. In animals with a "skull cap" the catheter was secured by inserting it through the L-shaped length of polyethylene tubing that was affixed to the skull. In the remaining animals the catheter was connected to a back-port similar to that described by Caine et al. (1993). Following catheter implantation the rats were allowed to recover for at least 4 days. During this period the catheters were flushed daily with 0.1 $\mathrm{ml}$ of heparin and an intravenous antibiotic was injected to minimize the likelihood of infections. Throughout the experiment the catheters were flushed at least once daily with $0.1 \mathrm{ml}$ of a heparin solution.

\section{Groups}

Rats were randomly assigned to one of the following experimental groups:

1. HOME groups. These animals received daily i.v. injections of either saline (HOME/saline) or amphetamine (HOME/amphetamine) in their home cages, using remotely-controlled syringe pumps.

2. NOVEL groups. These animals were transported each day from their home cage in the animal colony room to a distinct and relatively novel test environment (see below), where they immediately received an i.v. injection of either amphetamine (NOVEL/amphetamine) or saline (NOVEL/saline).

3. HABITUATION groups. Like the NOVEL groups, these animals were housed in the main animal colony and they were transported daily to the distinct test environment. However, after being placed in the test chamber they were left undisturbed for either 1 $\mathrm{hr}$ or $6-8 \mathrm{hr}$ prior to receiving a remotely-activated i.v. injection of amphetamine ( $1 \mathrm{hr}$ HABITUATION/ amphetamine and 6-8 hr HABITUATION/amphetamine) or saline (6- $8 \mathrm{hr}$ HABITUATION/saline; there was no $1 \mathrm{hr}$ HABITUATION/saline group).

It is important to emphasize that for all groups the test cages were identical, because the physical characteristics of the test environment can have a large effect on both the acute response to a drug (Beck et al. 1986; Ellinwood and Kilbey 1975), and on the induction of sensitization (Hirabayashi and Alam 1981).

\section{Procedures}

Acclimatization. Following catheter implantation, the rats that had been assigned to the HOME groups were transported to a climate-controlled and sound-attenuated testing room (white-noise was on at all times), where they were housed in the behavioral testing cages. The test cages consisted of opaque plastic round buckets with a flat-bottom floor $(25 \mathrm{~cm} \mathrm{ID,} 36 \mathrm{~cm} \mathrm{H})$. The floor of each cage was covered with granulated corncob bedding, and food and water were available ad libitum. These animals remained in these cages for the entire duration of the experiment, and were left undisturbed except for flushing their catheters daily (for details, see Crombag et al. 2000).

During this phase of the experiment the rats assigned to the NOVEL and HABITUATION groups remained in the main animal colony where they were housed in standard stainless steel hanging cages $(18 \times$ $25 \mathrm{~cm}$ ). The waste trays below the cages were covered with pinewood shavings. These rats were left undisturbed except for flushing their catheters daily.

Repeated Drug Treatment. During the drug treatment phase of the experiment the rats received, de- 
pending on their group assignments, repeated i.v. injections of either $0.5 \mathrm{mg} / \mathrm{kg}$ amphetamine or $0.9 \%$ saline. One injection per day was given for a total number of 12 or 14 treatments (balanced across groups), using the following procedures. On the morning of each test day the infusion lines for all groups were backloaded with $15 \mu \mathrm{l}$ of amphetamine or saline. The remainder of the line was filled with heparin, which was separated from the drug bolus by a small air bubble to prevent drug diffusion. The catheters of the rats in the HOME groups were then connected to the infusion lines. At the same time, the rats in the $6-8 \mathrm{hr}$ HABITUATION groups were transported from the animal colony to the testing room where they were placed into the test cages. They were immediately tethered and their catheters were connected to the infusion lines. The rats were then left undisturbed. Later during the day the rats of the $1 \mathrm{hr}$ HABITUATION groups were also transported to the test cages and tethered, and their catheters were connected to the infusion lines. Finally, $1 \mathrm{hr}$ later the rats in the NOVEL groups were transported to the test chambers and tethered. Immediately after their catheters were attached to the syringe pumps all groups were injected by remotely activating the syringe pumps. Thus, all groups received injections at the same time of the day, but the groups differed in the length of time that they were exposed to the drug treatment environment prior to drug administration.

Each i.v. injection consisted of an initial $20 \mu l$ of heparin (volume of catheter), followed by $15 \mu \mathrm{l}$ of amphetamine (or saline) followed by an additional $25 \mu \mathrm{l}$ of heparin. This volume was injected at a flow-rate of $20 \mu \mathrm{l} /$ min over a period of $3 \mathrm{~min}$ (i.e., the drug bolus was injected over a $45 \mathrm{sec}$ period). At the end of the $90 \mathrm{~min}$ test session the experimenter entered the testing room, the infusion lines were disconnected from the catheters and the catheters were sealed. Rats assigned to the NOVEL and the HABITUATION groups were returned to the animal colony, whereas the HOME groups remained in the test environment.

Withdrawal Phase. Following the last injection, treatments were discontinued for 6 days during which time animals were left undisturbed except for flushing the catheter daily, as during the acclimatization phase.

Amphetamine and Saline Challenge Tests. Following the withdrawal phase, all groups (including the saline control groups) received a challenge injection of 0.5 $\mathrm{mg} / \mathrm{kg}$ of amphetamine to test for the expression of behavioral sensitization, using the procedures described above. Finally, on the day after the amphetamine challenge test, all groups were tested for the expression of a conditioned response (CR) by administering a challenge injection of saline immediately after placement into the drug treatment environment (HOME groups remained in the test environment). Rotational behavior was recorded in $5 \mathrm{~min}$ intervals for a total of $90 \mathrm{~min}$.

\section{Catheter Patency}

Catheters were tested for patency after the first test session, after the repeated drug treatment phase, and after the amphetamine challenge test by intravenously injecting $0.1 \mathrm{ml}$ of the short-acting barbiturate Thiopental ${ }^{\circledR}$. Rats that did not become ataxic within 5 sec were excluded from the data analysis.

\section{Statistical Analyses}

Because the catheters were tested at several times during the experiment, and some animals were eliminated after each testing, the number of animals in each group varied for the different statistical comparisons (Ns are given in the relevant figure captions). Furthermore, all statistical comparisons were planned before the experiment was conducted, based on predictions and specific questions arising from previous studies.

Differences in the rotational response to an acute injection of amphetamine (first test session) were analyzed for differences between groups using unpaired Student's $t$-tests. The with-in group change in rotational behavior across test sessions (development of sensitization) was analyzed using paired $t$-tests (first vs. last test session) and group differences in the development of sensitization were assessed using two-way ANOVA's, with repeated measures on one factor (test session). The response to a challenge injection of amphetamine (to test for the long-term expression of sensitization) and saline (to test for the development of a CR) were compared for group differences using unpaired t-tests followed by two-way ANOVA's to test for differences between treatment conditions when appropriate. Because there was no $1 \mathrm{hr}$ HABITUATION/saline control group the $1 \mathrm{hr}$ HABITUATION/amphetamine group was compared to the NOVEL/saline group, which provided a conservative comparison.

\section{Drugs}

Atropine methyl nitrate was dissolved in $0.9 \%$ saline $(0.5 \mathrm{mg} / \mathrm{ml})$ and administered intraperitoneally (i.p., $0.2 \mathrm{mg} / \mathrm{kg}$ ) $10 \mathrm{~min}$ prior to anesthesia. General anesthesia was induced by injecting i.p. $52 \mathrm{mg} / \mathrm{kg}$ sodium pentobarbital (Butler Company, Columbus, $\mathrm{OH}$ ) supplemented with methoxyflurane when necessary (Metofane, Mallikrody Veterinary, Mundelein, IL). Desipramine hydrochloride (DMI) was dissolved in distilled water $(15 \mathrm{mg} / \mathrm{ml})$ and administered i.p. $(15 \mathrm{mg} /$ $\mathrm{kg}$ ) 20-30 min prior to 6-OHDA infusion. 6-Hydroxydopamine (2,4,5-trihydroxyphenethylamine) hydrobro- 
mide (6-OHDA) was freshly dissolved $(2 \mathrm{mg} / \mathrm{kg})$ in a cold $0.9 \%$ saline/ascorbic acid solution $(0.1 \mathrm{mg} / \mathrm{ml})$. Apomorphine hydrochloride was freshly dissolved (0.1 $\mathrm{mg} / \mathrm{ml}$ ) in $0.9 \%$ saline and administered s.c. in the neck $(0.05 \mathrm{mg} / \mathrm{kg})$. D-amphetamine sulfate was dissolved in buffered saline at $\mathrm{pH}$ 7.3. Catheter patency was tested by intravenously injecting the short acting barbiturate, Thiopental sodium ${ }^{\circledR}$, which had been dissolved in deionized water $(20 \mathrm{mg} / \mathrm{ml})$. Heparin, used to prevent blood clogging in the catheters, was freshly prepared on a regular basis in a $0.9 \%$ phosphate buffered saline solution ( 30 units $/ \mathrm{ml}$ ), and the $\mathrm{pH}$ was adjusted to 7.4. Finally, the antibiotic gentamicin $(15 \mathrm{mg} / \mathrm{ml})$ was used to prevent microbial growth. Drug doses refer to the weight of the salt. All drugs were purchased from Sigma (St. Louis, MO), unless noted differently.
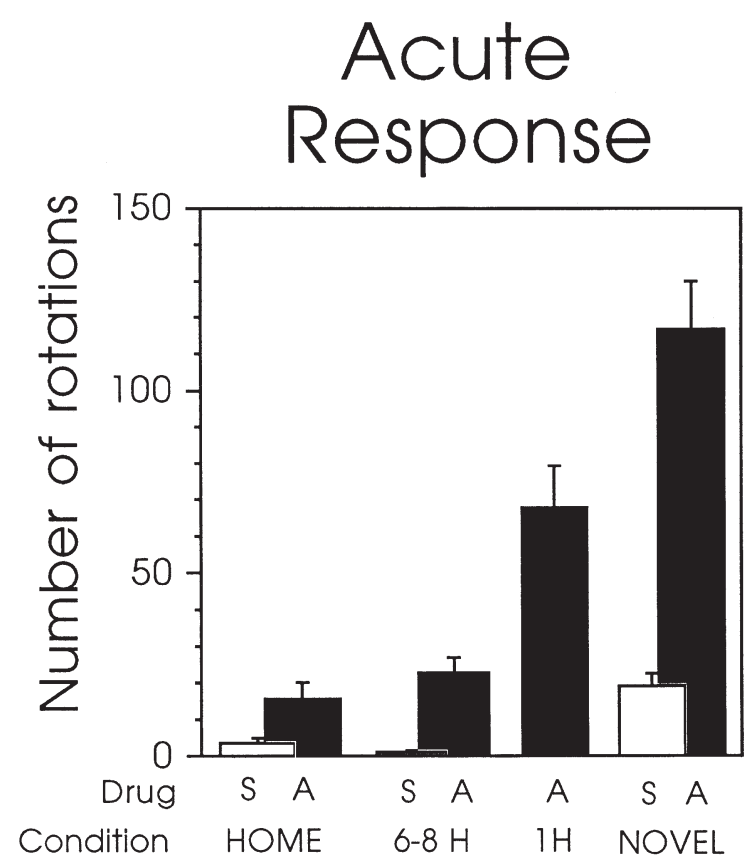

Figure 1. The mean $( \pm S E M)$ number of rotations (averaged over a 90 min test session) produced by an acute i.v. injection of $0.5 \mathrm{mg} / \mathrm{kg}$ amphetamine or saline given in the HOME environment (HOME/amphetamine, $\mathrm{N}=17$; $\mathrm{HOME}$ /saline, $\mathrm{N}=17$ ), immediately following placement into the NOVEL environment (NOVEL/amphetamine, $\mathrm{N}=$ 31; NOVEL/saline, $\mathrm{N}=20$ ), following $1 \mathrm{hr}$ (1 hr HABITUATION/amphetamine, $\mathrm{N}=17)$ or $6-8 \mathrm{hr}$ (6-8 hr HABITUATION/amphetamine, $\mathrm{N}=25 ; 6-8 \mathrm{hr}$ HABITUATION/ saline, $\mathrm{N}=8$ ) habituation to the test environment prior to drug administration. In all treatment conditions amphetamine produced an increase in rotational behavior relative to saline control groups, however, the magnitude of the acute response was dependent on the length of habituation to the drug treatment environment. Abbreviations: $S$, saline; A, amphetamine; $1 \mathrm{H}, 1 \mathrm{hr}$ habituation; 6-8 H, 6-8 hr habituation.

\section{RESULTS}

\section{Effect of Saline}

Figure 1 shows the number of rotations, averaged over $90 \mathrm{~min}$, following the first i.v. injection of saline in the HOME, NOVEL and HABITUATION groups. The first and subsequent injections of saline produced negligible rotational behavior in the HOME and the 6-8 hr HABITUATION groups (Figure 2). In the NOVEL group, however, there was a small increase in rotational behavior the first time the rats were placed into the test chamber and injected with saline $(t=5.76, \mathrm{df}=19, p<$ .001). This effect dissipated with repeated treatments, presumably because of habituation to the test environment across days (Figure 2).

\section{Repeated Treatment}

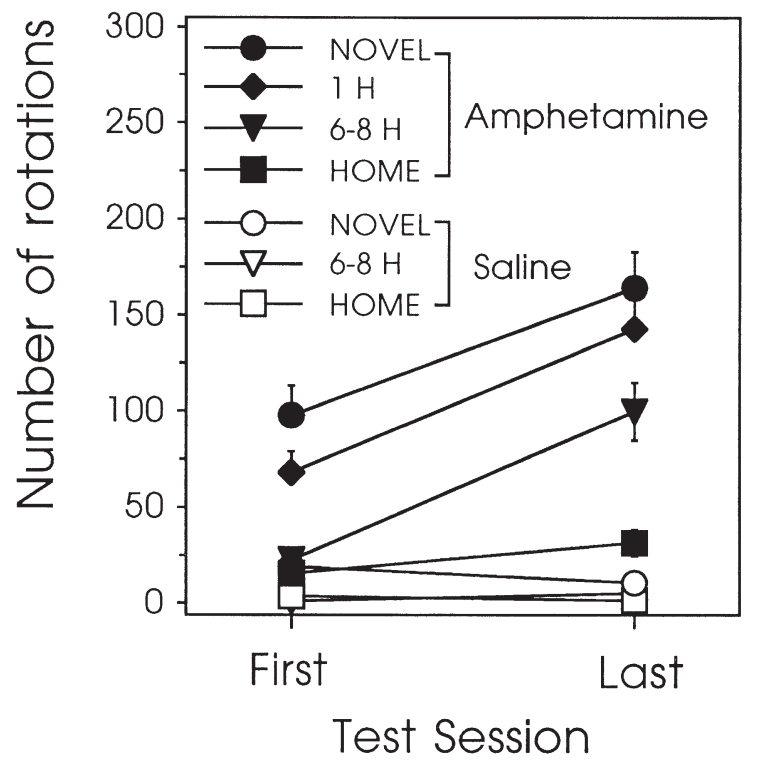

Figure 2. The mean $( \pm S E M)$ number of rotations (averaged for the $90 \mathrm{~min}$ test session) in response to the first and last injection of $0.5 \mathrm{mg} / \mathrm{kg}$ amphetamine or saline given in the HOME environment (HOME/amphetamine, $\mathrm{N}=17$; HOME/saline, $\mathrm{N}=16$ ), immediately following placement into the NOVEL environment (NOVEL/amphetamine, $\mathrm{N}=$ 20; NOVEL/saline, $\mathrm{N}=20$ ), following $1 \mathrm{hr}$ (1hr HABITUATION/amphetamine, $\mathrm{N}=17)$ or 6-8 hr (6-8 hr HABITUATION/amphetamine, $\mathrm{N}=20,6-8 \mathrm{hr}$ HABITUATION/ saline, $N=8$ ) habituation to the test environment prior to drug administration. Repeated treatments with amphetamine produced a robust sensitization in the NOVEL treatment condition, and when given after either $1 \mathrm{hr}$ or $6-8 \mathrm{hr}$ habituation to the test environment, but not when amphetamine was given in the absence of treatment related stimuli in the rat's home cage. 


\section{Effect of the First (Acute) Injection of Amphetamine}

Figure 1 also shows the number of rotations, averaged over $90 \mathrm{~min}$, following the first i.v. injection of $0.5 \mathrm{mg}$ / $\mathrm{kg}$ amphetamine. The first injection of amphetamine produced a significant increase in rotational behavior in all groups, relative to the appropriate saline treated control groups (NOVEL, $\mathrm{t}=5.84, \mathrm{df}=49, p<.0001 ; 1$ hr HABITUATION, $\mathrm{t}=4.43, \mathrm{df}=35, p<.001 ; 6-8 \mathrm{hr}$ HABITUATION, $\mathrm{t}=2.86, \mathrm{df}=31, p<.01$; HOME, $\mathrm{t}=$ $2.48, \mathrm{df}=32, p<.05)$. There were, however, large group differences in the magnitude of the acute response to amphetamine (Fig. 1). One hour of habituation to the test environment significantly attenuated the acute effect of amphetamine ( $1 \mathrm{hr}$ HABITUATION vs. NOVEL, $\mathrm{t}=-2.48, \mathrm{df}=46, p<.05)$. The response to amphetamine was decreased even more by $6-8 \mathrm{hr}$ of habituation $(1 \mathrm{hr}$ HABITUATION vs. $6-8 \mathrm{hr}$ HABITUATION, $\mathrm{t}=$ -4.26 , $\mathrm{df}=40, p<.01)$, and the $6-8 \mathrm{hr}$ HABITUATION group did not differ from the HOME group $(\mathrm{t}=-1.12$, $\mathrm{df}=40, p=.27)$.

\section{Effects of Repeated Injections of Amphetamine}

One index of sensitization is provided by a within-subjects comparison of amphetamine-induced rotational behavior on the first day of drug treatment versus the last day of drug treatment, as shown in Figure 2. The NOVEL, the $1 \mathrm{hr}$ HABITUATION and the 6-8 hr HABITUATION groups all showed sensitization, but the HOME group did not. That is, planned comparisons indicated that the response to amphetamine was greater during the last test session than during the first test session in the NOVEL group $(\mathrm{t}=3.46, \mathrm{df}=20, p<.01)$, the $1 \mathrm{hr}$ HABITUATION group $(\mathrm{t}=3.67, \mathrm{df}=6, p<$ $.05)$, and the 6-8 $\mathrm{hr}$ HABITUATION group $(\mathrm{t}=5.56, \mathrm{df}=$ $19, p<.0001)$, but not the HOME group $(\mathrm{t}=1.99, \mathrm{df}=$ $16, p=.064)$. Furthermore, there were no differences between the NOVEL and HABITUATION groups in the development of psychomotor sensitization, as assessed with two-way ANOVAs (Fs $<0.20, p s>.65$ ).

\section{Effects of an Amphetamine Challenge Injection}

A second, more conservative index of sensitization is provided by a between-subjects comparison of the psychomotor response to a challenge injection of amphetamine in saline versus amphetamine pretreated rats, as shown in Figure 3. Amphetamine pretreated rats showed a sensitized response in the NOVEL group $(\mathrm{t}=$ $3.70, \mathrm{df}=36, p<.001)$, the $1 \mathrm{hr}$ HABITUATION group (relative to NOVEL/saline; $\mathrm{t}=3.48, \mathrm{df}=22, p<.01$ ), and the 6-8 $\mathrm{hr}$ HABITUATION group $(\mathrm{t}=2.91, \mathrm{df}=25$, $p<.01)$. Furthermore, the absence of significant interaction effects following two-way ANOVAs indicated that there were no differences in the magnitude of sensitiza- tion between the NOVEL and 6-8 hr HABITUATION groups $(\mathrm{F}=.01, p>.92)$. An unpaired $t$-test indicated that there was also no difference in the magnitude of the behavioral response between the $1 \mathrm{hr}$ HABITUATION/amphetamine and NOVEL/amphetamine groups on the challenge test day $(\mathrm{t}=.85, \mathrm{df}=22, p<.40)$. In contrast, animals in the HOME group showed only a very small sensitized response $(\mathrm{t}=3.05, \mathrm{df}=31, p<$ .01 ), and the magnitude of sensitization was significantly less than in all other groups ( $\mathrm{Fs}>4.43, p \mathrm{~s}<.05$ ).

\section{Effects of Saline Challenge Injection}

Finally, to determine whether drug treatments resulted in the development of a conditioned response (CR), all groups were tested for their rotational response to a challenge injection of saline (Figure 4). Only data from

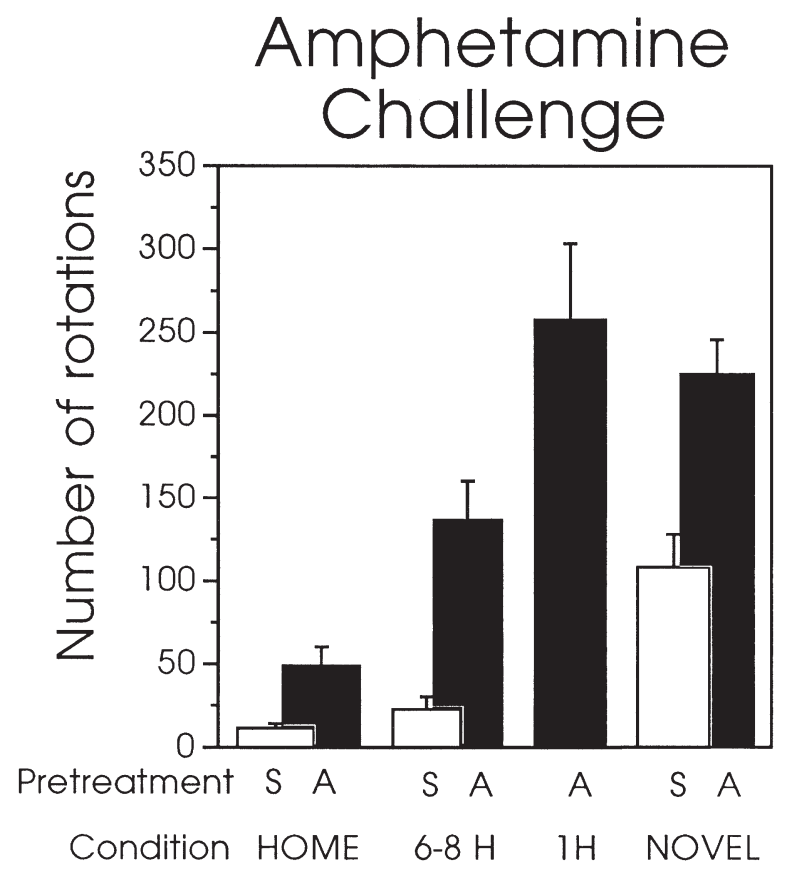

Figure 3. The mean $( \pm S E M)$ number of rotations (averaged for the $90 \mathrm{~min}$ test session) in response to a challenge injection of $0.5 \mathrm{mg} / \mathrm{kg}$ amphetamine for rats pretreated with saline or $0.5 \mathrm{mg} / \mathrm{kg}$ amphetamine in the HOME environment (HOME/amphetamine, $\mathrm{N}=16$; HOME/saline, $\mathrm{N}=$ $15)$, immediately following placement into the NOVEL environment (NOVEL/amphetamine, $\mathrm{N}=18$; NOVEL/saline, $\mathrm{N}=10$ ), following $1 \mathrm{hr}$ (1hr HABITUATION/amphetamine, $\mathrm{N}=7)$ or $6-8 \mathrm{hr}(6-8 \mathrm{hr}$ HABITUATION/amphetamine, $\mathrm{N}=$ $19,6-8 \mathrm{hr}$ HABITUATION/saline, $\mathrm{N}=8$ ) of habituation to the test environment. In all treatment conditions amphetamine pretreated rats showed a sensitized response to the challenge injection of amphetamine relative to saline pretreated rats. However, in the HOME treatment condition the expression of sensitization was smaller than in all other treatment conditions. See Figure 1 for abbreviations. 
the first $25 \mathrm{~min}$ of the test session were analyzed, because this captured the entire time course of the conditioned response (see Crombag et al. 2000). Figure 4 shows that only animals pretreated with amphetamine in the NOVEL environment showed a significant conditioned rotational response $(\mathrm{t}=3.27, \mathrm{df}=34, p<.01$; for the other groups, $p \mathrm{~s}>.79$ ).

\section{DISCUSSION}

The following major findings are reported. (1) The acute psychomotor response produced by an i.v. injection of $0.5 \mathrm{mg} / \mathrm{kg}$ amphetamine, and the psychomotor sensitization produced by repeated injections, were greater when drug treatments were given immediately after animals were placed into a distinct and relatively novel test environment, compared to when treatments were given in a physically identical environment, but in which the animals lived (i.e., at HOME). (2) Habituation to the test environment for 6-8 hr immediately prior to drug administration completely abolished the effect of environmental novelty on the acute psychomotor response to amphetamine. (3) As little as $1 \mathrm{hr}$ of habitua-
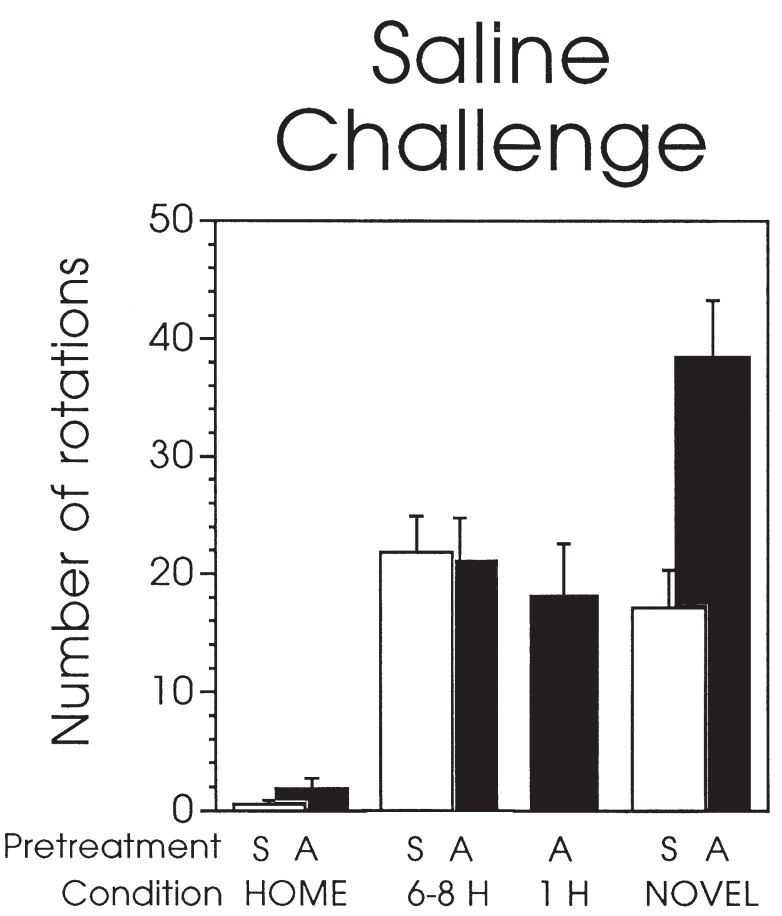

Figure 4 . The mean $( \pm S E M)$ number of rotations (averaged for the first $25 \mathrm{~min}$ of the test session) to challenge injection of saline for rats pretreated with amphetamine or saline in the HOME environment, immediately following placement into the NOVEL environment, or following $1 \mathrm{hr}$ or 6-8 hr habituation to the test environment (Ns were the same as in Figure 3). Only rats pretreated with amphetamine in the NOVEL environment showed a conditioned response. See Figure 1 for abbreviations. tion was sufficient to completely prevent the development of a conditioned rotational response (CR). (iv) In contrast, habituation to the test environment had no effect on its ability to facilitate the development of psychomotor sensitization. That is, rats habituated to the test environment for 1-8 $\mathrm{hr}$ prior to each drug injection sensitized to the same extent as rats that received an injection immediately after placement into the test cage (i.e., the NOVEL group).

These results demonstrate that the effect of environmental context on the acute psychomotor response to amphetamine can be dissociated from its effect on susceptibility to sensitization. This is particularly evident when comparing the HOME and 6-8 hr HABITUATION groups. These groups did not differ at all in their initial response to amphetamine, but repeated treatment with amphetamine produced only marginal sensitization in the HOME group, whereas in the 6-8 hr HABITUATION group amphetamine produced just as robust sensitization as seen in the NOVEL condition. Consistent with this, we have reported that the acute psychomotor response to cocaine (in contrast to amphetamine) is the same in HOME and NOVEL groups, but robust sensitization is induced only when repeated treatments are administered in a distinct test environment (Badiani et al. 1995b), unless high doses are used (Browman et al. 1998a). The idea that the acute psychomotor response to drugs, and their ability to induce sensitization, are dissociable phenomena is supported by behavioral genetic studies showing they are controlled by different genetic determinants (Logan et al. 1988; Phillips et al. 1995; Shuster et al. 1977).

\section{Effect of Environmental Novelty on the Acute Psychomotor Response}

The present study confirms our previous reports that environmental novelty enhances the acute psychomotor response to amphetamine, and that this effect does not extinguish with repeated pre-exposures to the same environment (Badiani et al. 1997; Browman et al. 1998b; Crombag et al. 1996). That is, the rotational response to amphetamine in rats exposed for the first time to the test environment (see NOVEL/amphetamine group in Figure 1) was almost identical to that seen in rats exposed to the same environment for 12-14 times in the absence of amphetamine (see NOVEL/saline group in Figure 3). Similarly, Drew and Glick (1988) reported that repeated pre-exposures to the test environment had no effect on the acute rotational response to amphetamine in neurologically intact rats. In contrast, when rats were habituated for as little as $1 \mathrm{hr}$ immediately prior to amphetamine treatment the effect of novelty was degraded, and after 6-8 $\mathrm{hr}$ of habituation the response to amphetamine was no different from that seen in animals permanently housed in the test envi- 
ronment. Although the term "habituation" is used in the literature to indicate either repeated pre-exposures to a test environment (i.e., prior to any treatment) or exposure to the test environment immediately prior to each treatment, clearly these two manipulations can have very different consequences.

The mechanism by which environmental novelty modulates the acute psychomotor response to amphetamine is not known. Mere exposure to a novel environment increases dopamine efflux in the prefrontal cortex and nucleus accumbens (Rebec et al. 1997, for example), and therefore, it is possible that the effect of a novel context simply adds to the effect of amphetamine on dopamine efflux. However, under the conditions of our experiments we have found that environmental novelty has no effect on the ability of amphetamine to enhance dopamine efflux in the caudate nucleus or the core or shell of the nucleus accumbens (Badiani et al. 1998, 2000a), so it is unlikely this is the mechanism.

Nevertheless, environmental novelty does have a large effect on the ability of amphetamine to engage neural activity in many brain regions, as indicated by the induction of c-fos mRNA (Badiani et al. 1998, 1999). It is possible this effect of environmental novelty is related to its action as a stressor. Forced exposure to a novel environment activates the hypothalamic-pituitary-adrenal (HPA) axis, increasing the release of corticosterone (Badiani et al. 1998; Friedman and Ader 1967; Hennessy and Levine 1977). Furthermore, adrenalectomy or pretreatment with metyrapone (a corticosterone synthesis inhibitor) are reported to attenuate the acute behavioral effects of psychomotor stimulant drugs (Marinelli et al. 1997a, 1997b; Piazza et al. 1994), and to block stress-induced potentiation of these effects (Deroche et al. 1992). Thus, it is possible that the enhanced acute response to amphetamine seen in the NOVEL group was due to elevated corticosterone levels. Consistent with this notion, the psychomotor response to amphetamine was reduced following $1 \mathrm{hr}$ of habituation, when corticosterone levels also would be reduced (Pfister and King 1976). After 6-8 hr of habituation to the test environment corticosterone levels should have returned to baseline (Pfister and King 1976), and at this time the effect of novelty on the acute psychomotor response to amphetamine was gone.

On the other hand, some researchers have reported that adrenalectomy has no effect on the acute psychomotor response to amphetamine (Cole et al. 1990a; Rivet et al. 1989), cocaine (Prasad et al. 1996), or nicotine (Johnson et al. 1995). Furthermore, Badiani et al. (1995c) found that adrenalectomy decreased locomotor and rearing hyperactivity produced by an i.p. injection of amphetamine in a novel test environment, but it had no effect on rotational behavior in rats with a unilateral lesion of the mesostriatal DA pathway. Of course, it is possible that stress-related hormones other than corti- costerone are involved. For example, Cador et al. (1993) have reported that the acute response to amphetamine is enhanced following an i.c.v. injection of corticotrophin releasing hormone $(\mathrm{CRH})$.

\section{Effect of Environmental Novelty on the Induction of Psychomotor Sensitization}

Consistent with our previous studies, repeated i.v. injections of $0.5 \mathrm{mg} / \mathrm{kg}$ amphetamine produced robust sensitization when given in a distinct environment, but only marginal sensitization when given at home. It has been suggested that a distinct environment may promote robust sensitization because contextual stimuli associated with drug administration acquire the ability to elicit conditioned psychomotor activation. The CR could add to the drug UR, thus facilitating the drug effect in that context (Hinson and Poulos 1981; Pert et al. 1990; Tilson and Rech 1973). However, the effects of habituation reported here do not support this idea. As little as 1 $\mathrm{hr}$ of habituation to the test environment prior to drug administration was sufficient to completely prevent the development of a conditioned rotational response, but neither $1 \mathrm{hr}$ nor 6-8 hr of habituation had any effect on the induction of sensitization. Similarly, Drew and Glick (1988) reported that the development of a CR was reduced by pre-exposure to the test environment, but this had no effect on amphetamine-induced sensitization. Additionally, amphetamine injections given directly into the ventral tegmental area induce behavioral sensitization, but do not result in the development of a CR (Stewart and Vezina 1988). Finally, we recently reported that signaling drug administration in the HOME environment using discrete stimuli (lights, tones, vibrations, and odors) is not sufficient to promote robust sensitization, even though such stimuli acquire CS properties (Crombag et al. 2000). We conclude, therefore, that the ability of environmental context to act as a traditional excitor (CS+) does not account for its ability to promote sensitization (Carey and Gui 1998; Hiroi and White 1989; Martin-Iverson and Fawcett 1996).

An alternative hypothesis is that drug injections in a distinct and relatively novel test environment facilitate sensitization by modulating the unconditioned stimulus properties of amphetamine, through mechanisms independent of associative learning. For example, as with the acute response, exposure to the novel environment may potentiate sensitization because of some action as a stressor. As discussed above, exposure to a relatively novel environment activates the HPA-axis (Friedman and Ader 1967), and repeated exposure can sometimes result in an increase in plasma corticosterone levels, over-and-above the levels produced by a single exposure to novelty (Hennessy 1991; Hennessy and Levine 1977). Consistent with this hypothesis are reports that (1) cross-sensitization occurs between 
drugs and stressors (Antelman et al. 1980); (2) adrenalectomy blocks the development of sensitization to the locomotor effects of amphetamine (Rivet et al. 1989) and nicotine (Johnson et al. 1995); and (3) central administration of a CRF antagonist attenuates the induction of amphetamine sensitization (Cole et al. 1990b).

On the other hand, Badiani et al. (1995c) found that adrenalectomy has no effect on the ability of environmental novelty to promote psychomotor sensitization, suggesting that drug-corticosterone interactions are not responsible for the effects reported here. Consistent with this view, we reported here that after $6-8 \mathrm{hr}$ of habituation, when corticosterone levels should have returned to baseline (Pfister and King 1976), animals still showed robust sensitization. Indeed, the effect of various stressors on corticosterone is relatively transient (Friedman and Ader 1967; Grota et al. 1997; Koolhaas et al. 1997), including the effect of novelty (Pfister and King 1976). This is difficult to reconcile with the notion that increased corticosterone levels are directly responsible for the group differences in sensitization we observed.

\section{CONCLUSIONS}

Whatever mechanism(s) account(s) for the ability of a distinct environmental context to promote sensitization, its effect clearly extends well beyond the immediate biobehavioral consequences of exposure to that environment. The mechanism could still be related to some stressor-like properties of a relatively novel environment, because as noted by Koolhaas et al. (1997, p 777), "stress induces a cascade of neurobiological processes. Each of the processes may have a different time course ranging from milliseconds, in the case of direct transduction processes, to minutes, hours, and days when modulatory processes are involved at the level of DNA transcription and peptide synthesis". It is particularly relevant, therefore, that Badiani and colleagues (1998) have reported that c-fos induction in the cortex, in the caudate, in the shell and core of the nucleus accumbens, and in other subcortical structures, is markedly different when an acute i.p. injection of amphetamine is given in a novel test environment, relative to when it is given in a rat's home cage. Furthermore, using double in situ hybridization of striatal neurons with probes for c-fos and for D1 and D2 receptor mRNA, these authors reported that amphetamine engages different neural circuitry depending on the environmental context in which it is administered. That is, amphetamine given at home induces c-fos expression primarily in D1 (but not D2) neurons, whereas when amphetamine is given in a novel environment c-fos is induced in both D1 and D2 mRNA-positive neurons (Badiani et al. 1999). We hypothesize, therefore, that environmental context may modulate the initial stage (immediate early gene expression) in a cascade of cellular processes that promotes neuroplasticity. Furthermore, the lack of any effect of 6-8 hr of habituation to the test environment suggests that whatever cellular processes are initiated by exposure to a distinct environment must render the brain susceptible to sensitization by drugs for a considerable period of time. That is, exposure to a distinct and relatively novel environment seems to produce a persistent change in some brain "state" that facilitates the ability of psychostimulant drugs to later induce whatever neuroplastic alterations are responsible for behavioral sensitization.

\section{ACKNOWLEDGMENTS}

Research supported by a grant from the National Institute on Drug Abuse (DA04294) to TER.

\section{REFERENCES}

Antelman SM, Eichler AJ, Black CA, Kocan D (1980): Interchangeability of stress and amphetamine in sensitization. Science 207:329-31

Badiani A, Anagnostaras SG, Robinson TE (1995a): The development of sensitization to the psychomotor stimulant effects of amphetamine is enhanced in a novel environment. Psychopharmacology 117:443-452

Badiani A, Browman KE, Robinson TE (1995b): Influence of novel versus home environments on sensitization to the psychomotor stimulant effects of cocaine and amphetamine. Brain Res 674:291-298

Badiani A, Camp DM, Robinson TE (1997): Enduring enhancement of amphetamine sensitization by drugassociated environmental stimuli. J Pharmacol Exp Ther 282:787-794

Badiani A, Morano MI, Akil H, Robinson TE (1995c): Circulating adrenal hormones are not necessary for the development of sensitization to the psychomotor activating effects of amphetamine. Brain Res 673:13-24

Badiani A, Oates MM, Day HEW, Watson SJ, Akil H, Robinson TE (1998): Amphetamine-induced behavior, dopamine release, and c-fos mRNA expression: Modulation by environmental novelty. J Neurosci 18:1057910593

Badiani A, Oates MM, Day HEW, Watson SJ, Akil H, Robinson TE (1999): Environmental modulation of amphetamine-induced c-fos expression in D1 versus D2 striatal neurons. Behav Brain Res 103:203-209

Badiani A, Oates MM, Fraioli S, Browman KE, Ostrander MM, Xue C-J, Wolf ME, Robinson TE (2000a): Environmental modulation of the response to amphetamine: dissociation between changes in behavior and changes in dopamine and glutamate overflow in the striatal complex. Psychopharmacology 151:166-174

Badiani A, Oates MM, Robinson TE (2000b): Modulation of morphine sensitization in the rat by contextual stimuli. Psychopharmacology 151:273-282 
Beck CHM, Chow HL, Cooper SJ (1986): Initial environment influences amphetamine-induced stereotypy: subsequently environment change has little effect. Behav Neural Biol 46:383-397

Breese GR, Traylor TD (1971): Depletion of brain noradrenaline and dopamine by 6-hydroxydopamine. Br J Pharmacol 42:88-99

Browman KE, Badiani A, Robinson TE (1998a): The influence of environment on the induction of sensitization to the psychomotor activating effects of intravenous cocaine in rats is dose-dependent. Psychopharmacology 137:90-98

Browman KE, Badiani A, Robinson TE (1998b): Modulatory effect of environmental stimuli on the susceptibility to amphetamine sensitization: A dose-effect study in rats. J Pharmacol Exp Ther 287:1007-1014

Cador M, Cole BJ, Koob GF, Stinus L, Le Moal M (1993): Central administration of corticotropin releasing factor induces long-term sensitization to D-amphetamine. Brain Res 606:181-186

Caine SB, Lintz R, Koob GF (1993): Intravenous drug selfadministration techniques in animals. In Sahgal A (ed), Behavioral Neuroscience, A Practical Approach, vol. II. New York, IRL Press at Oxford University Press, pp 117-143

Carey RJ, Gui J (1998): Cocaine conditioning and cocaine sensitization: What is the relationship? Behav Brain Res 92:67-76

Cole BJ, Cador M, Stinus L, Rivier C, Rivier J, Vale W, Le Moal M, Koob GF (1990a): Critical role of the hypothalamic pituitary adrenal axis in amphetamine-induced sensitization of behavior. Life Sci 47:1715-1720

Cole BJ, Cador M, Stinus L, Rivier J, Vale W, Koob GF, Le Moal M (1990b): Central administration of a CRF antagonist blocks the development of stress-induced behavioral sensitization. Brain Res 512:343-6

Crombag HC, Mueller H, Browman KE, Badiani A, Robinson TE (1999): A comparison of two behavioral measures of psychomotor activation following intravenous amphetamine or cocaine: Dose- and sensitizationdependent changes. Behav Pharmacol 10:205-213

Crombag HS, Badiani A, Maren S, Robinson TE (2000): The role of contextual versus discrete drug-associated cues in promoting the induction of psychomotor sensitization to intravenous amphetamine. Behav Brain Res 116:1-22

Crombag HS, Badiani A, Robinson TE (1996): Signalled versus unsignalled intravenous amphetamine: Large differences in the acute psychomotor response and sensitization. Brain Res 722:227-231

Deroche V, Piazza PV, Casolini P, Maccari S, Le Moal M, Simon H (1992): Stress-induced sensitization to amphetamine and morphine psychomotor effects depend on stress-induced corticosterone secretion. Brain Res 598:343-8

Drew KL, Glick SD (1988): Characterization of the associative nature of sensitization to amphetamine-induced circling behavior and the environment dependent placebo-like response. Psychopharmacology 95:482-487

Ellinwood EH, Kilbey MM (1975): Amphetamine stereotypy: the influence of environmental factors and prepotent behavioral patterns on its topography and development. Biol Psychiat 10:3-16

Friedman SB, Ader R (1967): Adrenocortical response to novelty and noxious stimulation. Neuroendocrinology 2:209-212

Grota LJ, Bienen T, Felten DL (1997): Corticosterone responses of adult Lewis and Fischer rats. J Neuroimmunol 74:95-101

Hefti F, Melamed E, Wurtman RJ (1980): Partial lesions of the dopaminergic nigrostriatal system in rat brain: biochemical characterization. Brain Res 195:123-37

Hennessy MB (1991): Sensitization of the plasma corticosterone response to novel environments. Physiol Behav 50:1175-9

Hennessy MB, Levine S (1977): Effects of various habituation procedures on pituitary-adrenal responsiveness in the mouse. Physiol Behav 18:799-802

Hinson RE, Poulos CX (1981): Sensitization to the behavioral effects of cocaine: Modification by Pavlovian conditioning. Pharmacol Biochem Behav 15:559-62

Hirabayashi M, Alam MR (1981): Enhancing effect of methamphetamine on ambulatory activity produced by repeated administration in mice. Pharmacol Biochem Behav 15:925-932

Hiroi N, White NM (1989): Conditioned stereotypy: behavioral specification of the UCS and pharmacological investigation of the neural change. Pharmacol Biochem Behav 32:249-258

Johnson DH, Svensson AI, Engel JA, Soderpalm B (1995): Induction but not expression of behavioural sensitization to nicotine in the rat is dependent on glucocorticoids. Eur J Pharmacol 276:155-64

Kimble GA (1947): Behavior strength as a function of the time between conditioned and unconditioned stimuli. J Exp Psychol 37:1-15

Koolhaas JM, Meerlo P, De Boer SF, Strubbe JH, Bohus B (1997): The temporal dynamics of the stress response. Neurosci Biobehav Rev 21:775-82

Lett BT (1989): Repeated exposures intensify rather than diminish the rewarding effects of amphetamine, morphine, and cocaine. Psychopharmacology 98:357-62

Logan L, Seale TW, Cao W, Carney JM (1988): Effects of chronic amphetamine in BALB/cBy mice, a strain that is not stimulated by acute administration of amphetamine. Pharmacol Biochem Behav 31:675-682

Marinelli M, Rouge-Pont F, De Jesus-Oliveira C, Le Moal M, Piazza PV (1997a): Acute blockade of corticosterone secretion decreases the psychomotor stimulant effects of cocaine. Neuropsychopharmacology 16:156-161

Marinelli M, Rouge-Pont F, Deroche V, Barrot M, De JesusOliveira C, Le Moal M, Piazza PV (1997b): Glucocorticoids and behavioral effects of psychostimulants. I: Locomotor response to cocaine depends on basal levels of glucocorticoids. J Pharmacol Exp Ther 281:1392-1400

Marshall JF, Ungerstedt U (1977): Supersensitivity to apomorphine following destruction of the ascending dopamine neurons: quantification using the rotational model. Eur J Pharmacol 41:361-367

Martin-Iverson M, Fawcett S (1996): Pavlovian conditioning 
of psychomotor stimulant-induced behaviors: has convenience led us astray? Behav Pharmacol 7:24-41

Pert A, Post R, Weiss SR (1990): Conditioning as a critical determinant of sensitization induced by psychomotor stimulants. NIDA Res Monogr 97:208-241

Pfister HP, King MG (1976): Adaptation of the glucocorticosterone response to novelty. Physiol Behav 17:43-46

Phillips TJ, Huson M, Gwiazdon C, Burkhart-Kasch S, Shen EH (1995): Effects of acute and repeated ethanol exposures on the locomotor activity of BXD recombinant inbred mice. Alcohol Clin Exp Res 19:269-278

Piazza PV, Deminière JM, Le Moal M, Simon H (1989): Factors that predict individual vulnerability to amphetamine self- administration. Science 245:1511-1513

Piazza PV, Marinelli M, Jodogne C, Deroche V, Rouge-Pont F, Maccari S, Le Moal M, Simon H (1994): Inhibition of corticosterone synthesis by Metyrapone decreases cocaine-induced locomotion and relapse of cocaine selfadministration. Brain Res 658:259-264

Pickens RW, Crowder WF (1967): Effects of CS-US interval on conditioning of drug response, with assessment of speed of conditioning. Psychopharmacology 11:88-94

Prasad BM, Ulibarri C, Kalivas PW, Sorg BA (1996): Effect of adrenalectomy on the initiation and expression of cocaine-induced sensitization. Psychopharmacology 125:265-273

Rivet JM, Stinus L, Le Moal M, Mormede P (1989): Behav- ioral sensitization to amphetamine is dependent on corticosteroid receptor activation. Brain Res 498:149-153

Rebec GV, Grabner CP, Johnson M, Pierce RC, Bardo MT (1997): Transient increases in catecholaminergic activity in medial prefrontal cortex and nucleus accumbens shell during novelty. Neuroscience 76:707-714

Robinson TE, Berridge KC (1993): The neural basis of drug craving: An incentive-sensitization theory of addiction. Brain Res Rev 18:247-291

Robinson TE, Browman KE, Crombag HS, Badiani A (1998): Modulation of the induction or expression of psychostimulant sensitization by the circumstances surrounding drug administration. Neurosci Biobehav Rev 22:347-354

Shuster L, Yu G, Bates A (1977): Sensitization to cocaine stimulation in mice. Psychopharmacology 52:185-190

Stewart J, Vezina P (1988): Conditioning and behavioral sensitization. In Kalivas PW, Barnes CD (eds), Sensitization in the Nervous System. Caldwell, NJ, Telford Press, pp 207-224

Tilson HA, Rech RA (1973): Conditioned drug effects and absence of tolerance to d-amphetamine induced motor activity. Pharmacol Biochem Behav 1:149-153

Weeks JR (1972): Long-term intravenous infusions. In Meyers RD (ed), Methods in Psychobiology. London, Academic Press, pp 155-168 